\title{
Neural Network for Positioning Space Station Solar Arrays
}

Ronald E. Graham

Lewis Research Center

Cleveland, Ohio

and

Paul P. Lin

Cleveland State University

Cleveland, Ohio

Prepared for the

$\begin{array}{lll}m & & \\ a & & n \\ 0 & n & n \\ 0 & n & n \\ 1 & 0 & n \\ 1 & u & 0 \\ 0 & 5 & 0\end{array}$

$\frac{3}{3}$

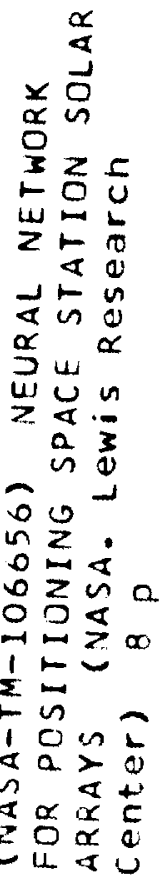

Symposium on Automatic Control in Aerospace sponsored by the International Federation of Automatic Control Palo Alto, California, September 12-16, 1994 



\author{
Ronald E. Graham \\ Conirol Systems Branch \\ NASA Lewis Research Center \\ Cleveland $\mathrm{OH} \mathbf{4 4 1 3 5}$
}

Paul P. Lin

Department of Mechanical Engineering

Cleveland State University

Cleveland OH 44115

\begin{abstract}
As a Shuule approaches the Space Station Freedom for a rendezivous, the Shuttie's renction control jet firings pose a risk of excessive plume impingement loads of Freedom solar arrays. The current solution to this problem, in which the arrays are locked in a fenthered position prior to the appronch, may be neither accurate nor robust, and is also expensive. An ahernative solution is proposed here: the active control of Freedom's beta gimbals during the approach, positioning the arrays dynamically in such a way that they remain feathered relative to the Shutle jet most likely to cause an impingement load. An artificial neural network is proposed as a means to determining the gimbal angles that would drive plume angle of attack to zero. Such a network would be both accurate and robust, and could be less expensive to implement than the current solution. A network was trained via backpropagation, and rewults, which compare favorably to the current solution as well as to some ocher alternatives, are presented. Oher training options are currently being evaluated.
\end{abstract}

\section{NOMENCLATURE}

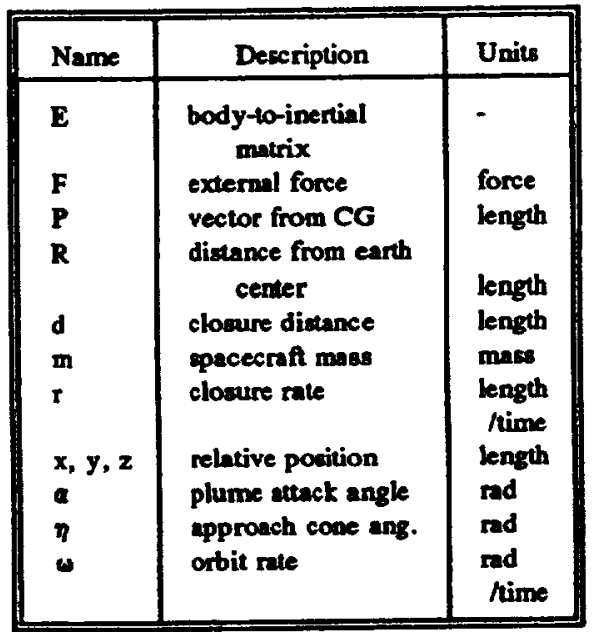

\section{INTRODUCTION}

The electrical power system of Space Station Freedom (SSF) draws power from the Sun by means of photovoltaic colar arrays. Beta gimbals rotute these arrays about their masts, enabling the arrays to maintain position relative to the sun or to reach some commanded orientation.

Berthing of the Shuttle with Freedom is accomplished by maneuvering the Shutcle within a amall distance of the station, as illustrated in Figure 1. During this maneuver, Shutule atuitude and approach clocure rate are corrected by its Reaction Control System (RCS) jets. It is possible at times for certain RCS jets to fire in the general direction of an array. The plume of a jet firing, illustrated in Figure 2, would in ach a case induce a structural load on the array. NASA's concern was that an excessive load from a plume impingement could cause a frilure of the array mast near the bets gimbal.

The baseline solution to the problem of excessive plume loeds is array feathering - the positioning of arrays prior to the approach such that their surfaces are parallel to the direction vector of a critical plume, and the mubsequem locking of the gimbals. The locking mechunism design limits error margin in fenthered povition. The structural redeaign also meane a large coet increase to be incurred by the Space Stution prognm, as is the case with mont redexign [1].

An alternative to this baseline solution is proposed: leave the bets gimbals active during approach, use their comrol systems to dynamically increment the feathered position of the arrays, and uac an artificinl neural network (ANN) to generate commanded gimbal angle. Active gimbal control allows for greater error margin in feathered pocition than do locked amays, and active control also enables the gimbals to reject disturbances within the capability of their motors.

A neural network design is proposed thrt will provide gimbal commands that drive the angle of attack of plumes on the arrays to near zero. The network was trained via backpropagation, using as an objective function the error between optimal and actual beta gimbal commanded angle. The rewultine propoeed control anchitecture is shown by block diagram in Figure 3.

\section{APPROACH MODEL}

During approach, the Shuttle astroasuts will keep the clomre velocity somewhere near a defined function of the closure distance. Experimental work done in this area [3] led to the adoption of the so-called "0.15 Rule," which is achieved by controlling the clomure rate to near 0.1 per cent of the clooure distance, given like units. 
The atronats have a second goal: that of maintaining the line of right (LOS) within pre-set limits. This is done (1) to enmble the Shutle to remnin aligned with the target with as few lateral RCS firings as postible, and (2) to minimize the effects of LOS rates on the atronuts' perspective of the target [5]. These objectives lead to the recommendation that the astronauts maintain position within an "approach cone," (as shown in Figure 2) with vertex at the berthing point of the target and predetermined hatf-angle.

The SSF and the Shutle are both modeled as a single rigid body with six degrees of freedom. The relative motion of the two bodiea in cortrolled by the Shuttle RCS, and follows the $0.1 \%$ Rule and ays within a S-degree approach cone. The equations of upproach dynamice are in Shuttle body-fixed coondinates.

The equation for motion in the nadir direction is

$$
\begin{aligned}
\frac{F_{x t}}{m_{s}} & +\frac{F_{E F}}{m_{f}} \\
& =\frac{d^{2} x}{d t^{2}}-2 \omega \frac{d z}{d t}-\omega^{2} x
\end{aligned}
$$

and for motion ungential to the orbits,

$$
\begin{aligned}
\frac{F_{s s}}{m_{s}} & -\frac{F_{x z}}{m_{f}} \\
& =\frac{d^{2} z}{d t^{2}}+20 \frac{d x}{d t}
\end{aligned}
$$

and for out-of plane motion,

$$
\frac{F_{y}}{m_{s}}-\frac{F_{y}}{m_{p}}=\frac{d^{2} y}{d t^{2}}
$$

The motion between two berthing points, one on each body and eeparnted from their reppective $C G$ by a vector $Q_{F}$ and $P_{\mathcal{S}}$, is given by

$$
\begin{aligned}
& \left.\frac{d v}{d t}\right|_{s / z}=\left[\frac{d^{2} x}{d t^{2}} \frac{d^{2} y}{d t^{2}} \frac{d^{2} z}{d t^{2}}\right]^{T} \\
& +\frac{d \theta_{v}}{d t} \times P_{s}+\theta_{g} \times\left(\omega_{s} X P_{s}\right) \\
& -\frac{d \theta_{r}}{d t} \times p_{p}-\theta_{p} x\left(\theta_{p} x p_{p}\right) \\
& =\left[\begin{array}{lll}
\frac{d v_{x}}{d t} & \frac{d v_{y}}{d t} & \frac{d v_{z}}{d t}
\end{array}\right]^{T}
\end{aligned}
$$

The critical parameters in proximity operations analysis are thowe that pertain to the $0.1 \%$ Rule and the approach cone. The clocure rate is given by

$$
r=\left.\int_{0}^{t} \frac{d v}{d t}\right|_{s / F} d t
$$

and elowre distance is given by

$$
\begin{aligned}
d & =\int_{0}^{t} x d t \\
& =\left[\begin{array}{lll}
d_{x} & d_{y} & d_{z}
\end{array}\right]^{T}
\end{aligned}
$$

Angular position within the approach cone is given by

$$
\begin{aligned}
& \eta_{x}=\tan ^{-1}\left(d_{x} / d_{x}\right) \\
& \eta_{y}=\tan ^{-1}\left(d_{y} / d_{z}\right)
\end{aligned}
$$

Aritude and poesition control of the Shutle in provided by 44 RCS joth, of which the firt 38 bave thruat capabilities ranging from sbout 690 to about 880 Bf. The other six offer $25 \mathrm{lbf}$ of thruet and are eutomatically controlled curing proximity operations.

A simple conerollet was used 10 simulate the behavior of the perfect aturoneut. I wasn't importane for this rudy that flight dat be matched exactly - the goal was to creale trining datu that gave "optimal" gimbal angles for various combination of the six availuble inputs.

Of aix RCS firine combination obuerved, as shown in Table 1 , only three hed any chance of causing an impingement on en array: jets used for braking (9-29-32) and thowe uned for out-of plase motion (5-22 or 7-25). Flight date indicuten a trenation of plume riak from one type of firing to the otber al clomure dienence decreanes.

Plume inpingemeat force is a function of angle of attack and cloaure diatance, which indicates the plume angle of atack (over which the beth gimbals can have some whority) and clowure diatance are two fundamental parnmeters 10 consider in minimizing impingement force.

Feathering worens that plume angle of anack can be minimized throughout the maneuver. Simulation shown that zero angle of atrack can be achieved if the arrays are lewed abour ten degrees during the maneuver, and if the appronch cone is exupuloudy followed during the transition period from braking to out-of-plane plume damage risk.

Both the SSF and the Shutule are actively controlled during this maneuver. For each of the two crnt, high-fidelity anitude control myem models were employed. Artitude control for Freedom [9] is eccomplished through the use of ceven RCS jets, pulaing in groups of three.

The beth gimbalo consid of direct-drive motors and are controlied via a PDD algorithm. The beta gimbal control law allowe for parameter uncertainty in electric motor dead zone [10] and in gimbal beariog friction [11]. The beta gimbals are active here for dynamic feathering. 


\section{NEURAL NETWORK SOLUTION}

An artificial neural network, such as shown in Figure 4, has as in its simplest forms the following ingredients: neurons (or nodes), which themselves consist of a weighted summer, a linear transfer function and a non-dynamic nonlinear limiting function; inputs and outputs based on the physics of the problem; and a learning mechanism that takes advantage of known data, which is readily available here.

This problem appears to be well-suited to a neural network solution in that it takes advantage of well-known characterietics both of the beta gimbals and of Shutle proximity operations. Hunt et. al. [16] lists properties of ANNB that are auitable for control applications:

- Theoretical ability to epproximate arbitrary nonlinear mappings;

- Directly aritable to parallel processing architecture.

- Directly applicable to multivariable systems.

Kohonen [17] points our that "...one calegory of problems which is sometimes believed to be amenable to 'neural computing' consists of various optimization tasks" [emphasis mine], and this task certainly falls into that category.

Desirable features of a neural network for this problem include:

- Simplicity
- Cos effectiveness
- Large amount of data
- Deaign atage not time-critical
- Smooth motion commands

Characteristics of this problem which may be exploiled are:
- Astronaut behavior
- Beta gimbal behuvior
- Jet firing behavior
- Anitude control behavior
- Ground command behavior
- Complete availability of input data

Clancy et. al. [18] opted for a single hidden layer, and the use of radial basis functions (RBFy) as the neuronal activation functions. The advantage of RBFs for a problem such as this is that they can be uned to claseify inputs wherever they fall in the input epace. Clancy's work yielded a large hidden layer, slthough his results were otherwive encouraging.

The network design used for proof-of-concept was trained via backpropagation [19]. The inquts used here are as follows:

- clowure distance
- cloeure rate
approach cone position (two values)
- approach cone rate (two values)

The nonlinearity mua be continuously differentiable. If the inputs are known to vary between zero and one, Rumelhart and others auggest the une of a sigmoid function - in this case, the inpuls may be of either sign, 80 a hyperbolic tangent function was used.
Of the various learning methods available, backpropagation is commonly used in practice. It is efficient (depending on the problem), relatively simple to understand, and readily available in various algorithms via shared software.

The training data for this problem was selected with the following assumptions:

(1) Datu taken from simulations of appraach, using "ideal" astronaut behaviour.

(2) Dats from simulations ampled every 1 second of approach, for 500 data points per simulation run.

(3) Runs chosen on the basis of initial conditions of $x$ and $y$ clowure position and $x, y$ and $z$ closure rate, with two parameters varied from nominal for each run. This procedure produced 21 simulation runs (for a total of 10500 data points), described by Table 1 .

There is a constant difference in geometry berween the two beta gimbals only, and the resulting weights show that the same feature in the error aurface ahould impact both gimbal commands in approximately the same way. The network error is plotted as a function of 1000 passes through the training data in Figure 5.

After 24000 passes through the training data, the network achieved very slow convergence, taken for this study as a minimum. The resulting weights were tested in the approach simulation, with the following results, in terms of how the setwork error wal divided among the 21 training scenarios, as shown in Table 2.

The term "target witching" indicates that the primary jet the amy is being feathered for is switching from z-braking 10 one of the two out-of-plane jets, or vice-vern. For come of the training scemarios, particularty thoee in which initial conditions had the approach offiset out-of-plane, one would expect a great deal of witching back and forth between braking and out-of-plane firings, and the determination of cptimal commanded gimbal angle reflects this effect. In fact, this in exactly the effect that the neural petwork mual be designed to schieve: some tradeoff between feathering for braking firings and out-of-plane firings. As one might guess, the network performs much better for training runs in which there is little or no switching, and not as well when there is a great deal of switching. The network tries to fair a curve comewhere between feathering for braking and for out-of-plane firings, which may be sufficient for the problem, since auch a curve would probably reduce the angle of atuack of a plume from either jet to within one degree.

Perhapt more imporant is the idea that the optimal beta gimbal angle for following even a single jet sweeps through reveral degrees during the 500 seconds of appranch examined here. That means that the solution involving locked gimbals is very reatrictive, in that the angle of attack will at some point in the approach exceed the accuracy afforded by the locking mechanism.

\section{CONCLUSIONS}

The gimbal lock solution can achieve as its best accuracy the angle between adjacent locking points. Thit accurncy, however, only represems two locking points - which of course ascumes the optimal locking point is chosen. The locking mechanism is a much coarser solution otherwise. 
The baceline decign fall short in the following areas:

\begin{tabular}{|c|c|c|c|c|c|}
\hline \multirow[t]{2}{*}{ f } & \multicolumn{5}{|c|}{ Initial Conditions (in or in/s) } \\
\hline & $\mathbf{x}$ & $\frac{d x}{d t}$ & $\mathbf{y}$ & $\frac{d y}{d t}$ & $\frac{d z}{d t}$ \\
\hline 1 & 0 & .0 & 0 & .0 & .3 \\
\hline 2 & 30 & -.1 & 0 & .0 & .3 \\
\hline 3 & 0 & .0 & 30 & -.1 & .3 \\
\hline 4 & 30 & .0 & 0 & .0 & .4 \\
\hline 5 & 0 & -.1 & 30 & .0 & .3 \\
\hline 6 & 0 & .0 & 0 & -.1 & .4 \\
\hline 7 & -30 & .0 & -30 & .0 & .3 \\
\hline 8 & 0 & .1 & 0 & .1 & .3 \\
\hline 9 & 0 & .0 & -30 & .0 & .2 \\
\hline 10 & -30 & .0 & 0 & .1 & 3 \\
\hline 11 & $\mathbf{0}$ & .1 & $\mathbf{0}$ & .0 & .2 \\
\hline 12 & 30 & .0 & $\mathbf{0}$ & .1 & .3 \\
\hline 13 & 0 & -.1 & 0 & .0 & .2 \\
\hline 14 & -30 & .0 & 30 & .0 & .3 \\
\hline 15 & $\mathbf{0}$ & .1 & 0 & -.1 & .3 \\
\hline 16 & 0 & .0 & -30 & .0 & .4 \\
\hline 17 & -30 & .0 & 0 & .0 & .4 \\
\hline 18 & 30 & .1 & 0 & .0 & .3 \\
\hline 19 & 0 & -.1 & -30 & .0 & 3 \\
\hline 20 & 0 & .0 & 30 & .1 & .3 \\
\hline 21 & 0 & .0 & 0 & -.1 & .2 \\
\hline
\end{tabular}

- It depends too heavily on a priori knowledge to get the right feathering angles.

- I is not simple, as the structural/mechanical redesign affects too many other components.

- It is not robun with respect to Shuttle motion.

The neural network proposed bere could be trained and retrained a seceusary. It can colve the optimization problem to (for practical purposes) whatever accuracy is meeded. It is simple, in that only the beth gimbals are involved - just as in the baseline solution, only without a mechanical redesign. And it is robure, as the neural network can be trained to respond to whulever relative motion combination are of intereat.

Any structural design change in Freedom may add reveral million dollars to the Stution's overall price tag. Software design changes are aleo expensive, but depend on the onder and sccuracy of the algorithm to be implemented.

Any solution to be adopted must minimize engineering derign and manufacture time. A structural redexign may delay other appect of the etructure, e.g. modal teating and component qualification. A coftware design solution may require training of engineering personnel and axtronnuts.

The setwork design proponed bere was the remult of training easentially by trial and error. I may be that 100 much stemetion was paid to avoiding local minima, and that the error surface is in reality flat (or gendly tloped) and rough (based on target switching). Reweanchers must decide whether this caution is critical or not, and if it is, decide whether to proceed by trial and exror or to antomite the procese, via simulated annealing of pertupe a "Monse Carlo" spprosch with a large number of atarting points. The approach tuken here lod to a deciga in an acceptably timely manner, and without using exceavive CPU, for proving the neural network concept.

Backpropagation learming is in this case wow. Again, if the network design is nol time-critical, a designer could realize reveral different designs tha work. This may not, however, be sceeptable in trining a finel network design for cotware coding at the ground intion. Backpropagation is in wide enough use that variants of the algorithm that run much facer than the original may be found via anonymous file tranfer prolocol at computer sites all over the work.

Altersutively, an appronch wuch as Clancy's could be adopted - a redial baxis function neural networt. The problem with the nadial basio function approech is that the complexity of these networts goes up dratically as inputa are added, or as the error auriace takes on more features. This tends to be true to come extext even when nodes are not selected randomly: Clancy extimated over $\mathbf{4 0}$ neurons in the hidden layer, with a design based on fewer training runs than were employed here.

The existing problem of risk of excessive Shutte RCS jet phume loads on Space Station Freedom wolar arrays during approech has been examined. The baseline solution to the problem, locking the arrays in a feathered position, is considered here to be neither eccurnte nor robush, and is very expentive. A proponal is made to replace the baseline colution with one in which the arrays are positioned dynamically during approach, using the exixting beta gimbalb. The gimbal commanded angles would be

The accuracy needed in plume angle of attack must be determined both by proximity operations and loads specialists, since it involves both geometry and structural dynamice. 
provided via a ground-implementable artificial neural network, a solution that provides greater accuracy and robustness, and is likely to do so at less cost.

\section{REFERENCES}

[1] Lawler, A. "Contractors Wam NASA of Looming Sution Cout Hikes." Space News, Vol. 4, No. 45, pp. 1 and 28, November 15-28, 1993.

[ 2] Yunis, I. S. and K. S. Carney. The Application of Structural Reliability Techniques to Plume Impingement Loeding of the Space Station Freedom Photovoltaic Array." NASA technical memo 105949 and AIAA paper 93-1338, 34h Structures, Structural Dynamics and Materials Conference, April 1993.

[ 3] Brody, A. R. "Evaluation of the '0.1\% Rule for Docking Maneuvers." Joumal of Spacecraft and Rockels, Vol. 27, No. 1, Jan.-Feb. 1990, pp. 7-8.

[ 4] Meshcheryakov, I. P., V. P. Sal'nitskii and A. P. Nechaev. "Engineering-Paychological Study of Information Imaging Systems." Kosmicheskie Issledovaniva, Vol. 16, No. 3., pp. 453-455, MayJune 1978.

[ 5] Haines, R. F. "Space Vehicle Approach Velocity Judgments Under Simulated Viaual Space Conditions." NASA technical memo 89437, August 1987.

[6] Anthony, T. C., B. Wie and S. Carroll. "PulseModulated Control Synchesia for a Flexible Spacecratt." Journal of Guidance, Control and Dynamice, Vol. 13., No. 6, Nov.-Dec. 1990, pp. 1014-1022.

[ 7] Ghowh, T., B. Muniz, ]. Cheng and M. Nall. "Space Stetion Solar Array Pointing Syatem for Control/ Structure Interaction Study Using CO-ST-IN for Modal Reduction." Preserded at the 1993 MSC World Users' Conference, May 1993.

[ 8] Carney, K. S., R. E. Graham, D. E. Kyr and P. Btelloch. "Detection of Pocential Space Station Control/Structure Interation with CO-ST-IN." Presented at the Third NASADOD Control/Structures Interaction Technology Conference, February 1989.

[ 9] Clubb, G. et. al. "Candidate Optimal Group (COG)." McDonnell.Douglas Space Syatems Division memo SP-M-240, September 1991.

[10] hnculescu, G. D. and J. J. Klop. 'Classical and Adaptive Control Algorithms for the Solar Array Pointing Syutem of the Space Station Freedom." Prewented at the first IEEE Conference on Control Application, September 1992.

[11] Schoemwald, D. A., U. Ozgüner and R. E. Graham. -Space Station Freedom Beta Gimbal Control Via Sensitivity Models." NASA technical memo 106000 , presented at the first IEEE Conference on Control Applications, January 1993.

[12] Cheng, J. K. "Solar Array Beta Gimbal Digiul Control Analyzis." Rockwell International, Rockeldyne Division Engineering Product Document EID-00988, Jamuary 1992.

[13) Meirovitch, L. and R. D. Quinn. Maneuvering and Vibration Control of Flexible Spacecraft." Joumal of the Astronautical Sciences, Vol. 35, July-Sepl. 1987, pp. 301-328.

[14] Schoenwald, D. A. and Ū. Ōzgüner. "On Combining Slewing and Vibration Control in Flexible

Manipulators Via Singular Perturbations." Presented at the 29th IEEE Conference on Decision and Control, December 1990.

[15] Wie, B., A. Hu and R. Singh. "Multibody
Ineraction Effects on Space Station Attiude Control and Momentum Management." Journal of Guidance, Control and Dynamics, Vol. 13, No. 6, Nov.-Dec. 1990, pp. 993-999.

[16] Hunt, K., D. Sbarbaro, R. Zbikowski and P. Gawthrop. "Neural Networks for Control Systems A Survey." Automatica, Vol. 28, No. 6, pp. 1083$1112,1992$.

[17] Kohonen, T. "An Introduction to Neural Computing." Neural Networks, Vol. 1, pp. 3-16, 1988.

[18] Clancy, D. J., Ü. Özgüner and R. E. Graham. "Positioning Space Station Freedom Solar Arrays with a Radial Basis Function Neural Network." To be publiahed as a NASA-TM, 1993.

[19] Rumelhart, D., G. Hinton and R. Williams. "Learning Representations by Back-Propagating Errors." Nature, Vol. 323, No. 9, pp. 533-535, October 1986.

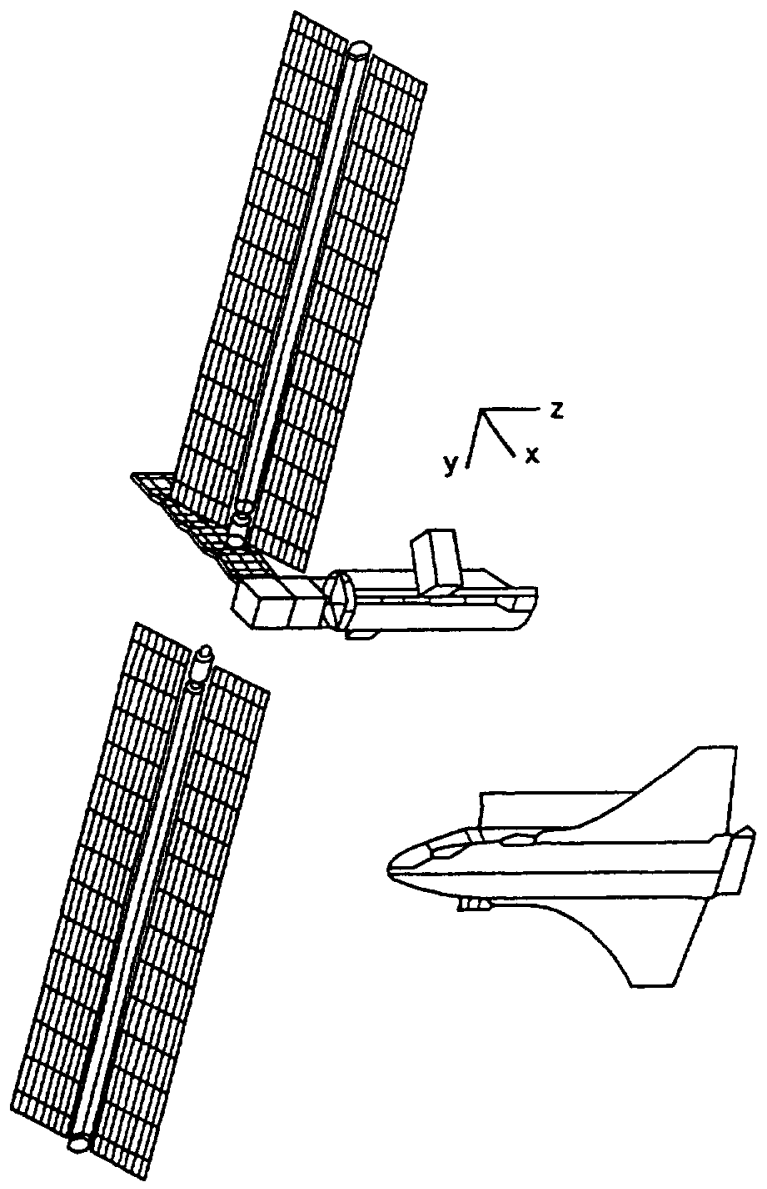

Figure 1.- Shuttle approach to SSF stage configuration SC-2. 


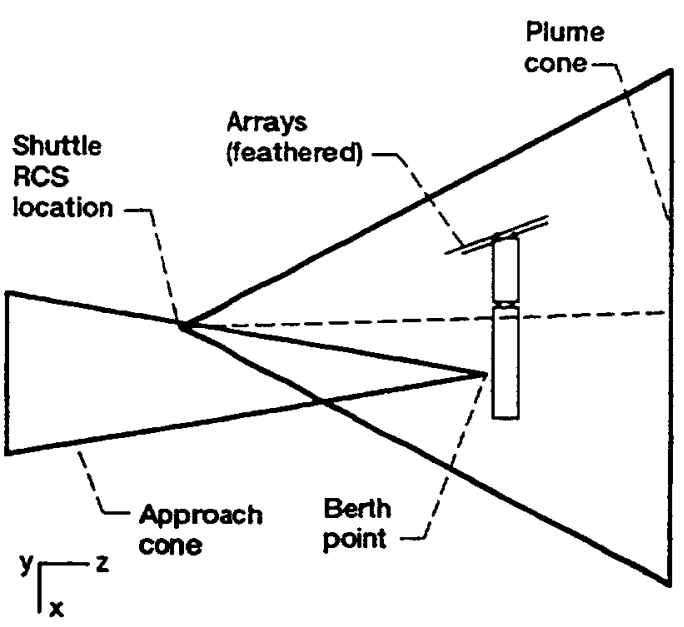

Figure 2-Geometry of plume impingement.

Functional control block diagram

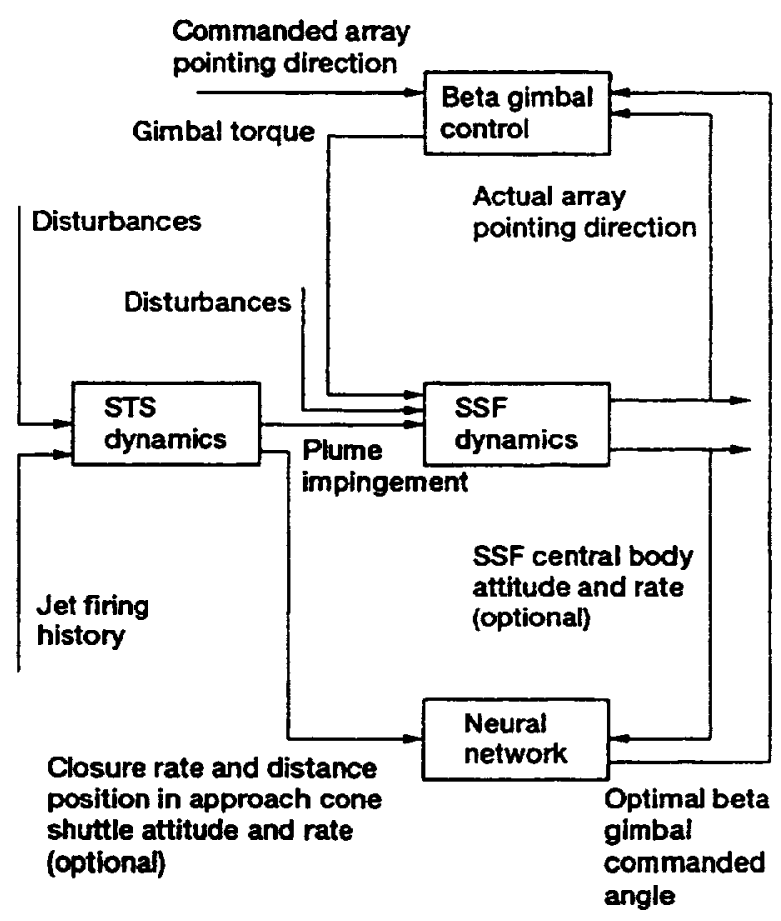

Figure 3.-Block diagram of proposed feathering control.

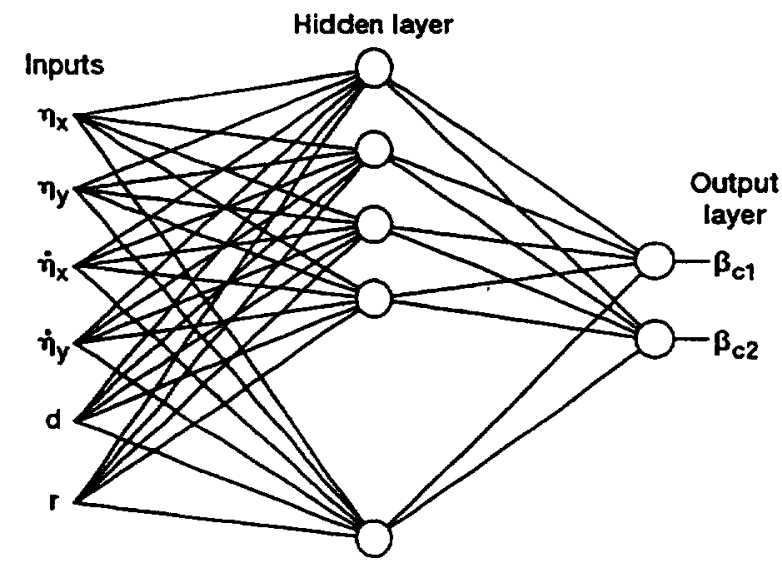

Figure 4.-Artificial neural network.

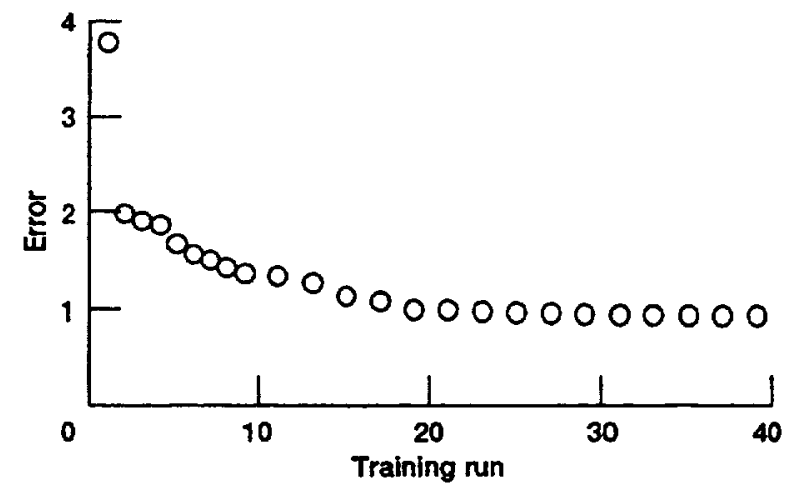

Figure 5.-Network error as a function of training run. 


\begin{tabular}{|c|c|c|}
\hline \multicolumn{2}{|c|}{ REPORT DOCUMENTATION PAGE } & $\begin{array}{l}\text { Form Approved } \\
\text { OMB No. 0704-0188 }\end{array}$ \\
\hline \multicolumn{3}{|c|}{ 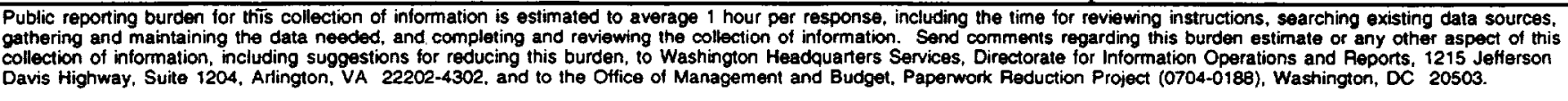 } \\
\hline 1. AGENCY USE ONLY (Leave blank) & $\begin{array}{r}\text { 2. REPORT DATE } \\
\text { June } 1994\end{array}$ & $\begin{array}{l}\text { D DATES COVEAED } \\
\text { echnical Memorandum }\end{array}$ \\
\hline \multicolumn{2}{|c|}{$\begin{array}{l}\text { 4. TITLE AND SUBTITLE } \\
\text { Neural Network for Positioning Space Station Solar Arrays }\end{array}$} & \multirow{2}{*}{ 5. FUNDING NUMBERS } \\
\hline \multicolumn{2}{|c|}{$\begin{array}{l}\text { 6. AUTHOR(S) } \\
\text { Ronald E. Graham and Paul P. Lin }\end{array}$} & \\
\hline \multicolumn{2}{|l|}{$\begin{array}{l}\text { National Aeronautics and Space } \\
\text { Lewis Research Center } \\
\text { Cleveland, Ohio } 44135-3191\end{array}$} & $\begin{array}{l}\text { 8. PERFORMING ORGANIZATION } \\
\text { REPORT NUMBER } \\
\text { E-8969 }\end{array}$ \\
\hline \multicolumn{2}{|c|}{ 9. SPONSORING/MONITORING AGENCY NAME(S) AND ADDRESS(ES) } & $\begin{array}{l}\text { 10. SPONSORINGMONITORING } \\
\text { AGENCY REPORT NUMBER } \\
\text { NASA TM-106656 }\end{array}$ \\
\hline \multicolumn{3}{|c|}{$\begin{array}{l}\text { 11. SUPPLEMENTARY NOTES } \\
\text { Prepared for the Symposium on Automatic Control in Aerospace sponsored by the International Federation of Automatic Control, Palo } \\
\text { Alto, California, September 12-16, 1994. Ronald E. Graham, NASA Lewis Research Center, and Paul P. Lin, Cleveland State } \\
\text { University, Department of Mechanical Engineering, Cleveland, Ohio } 44115 \text {. Responsible person, Ronald E. Graham, organization } \\
\text { code 4110. (216) 433-5178. }\end{array}$} \\
\hline \multicolumn{2}{|c|}{ 12a. DISTRIBUTIONAVAILABILITY STATEMENT } & 12b. DISTRIBUTION CODE \\
\hline
\end{tabular}

13. ABSTRACT (Maximum 200 words)

As a Shuttle approaches the Space Station Freedom for a rendezvous, the Shuttle's reaction control jet firings pose a risk of excessive plume impingement loads of Freedom solar arrays. The current solution to this problem, in which the arrays are locked in a feathered position prior to the approach, may be neither accurate nor robust, and is also expensive. An alternative solution is proposed here: the active control of Freedom's beta gimbals during the approach, positioning the arrays dynamically is such a way that they remain feathered relative to the Shuttle jet most likely to cause an impingement load. An artificial neural network is proposed as a means to determining the gimbal angles that would drive plume angle of attack to zero. Such a network would be both accurate and robust, and could be less expensive to implement than the current solution. A network was trained via backpropagation, and results, which compare favorably to the current solution as well as to some other alternatives, are presented. Other training options are currently being evaluated.

14. SUBJECT TERMS

Spacecraft dynamics; Spacecraft operations; Artificial neural networks

15. NUMBER OF PAGES

17. SECURITY CLASSIFICATION OF REPORT Unclassified
18. SECURITY CLASSIFICATION OF THIS PAGE

Unclassified
19. SECURTYY CLASSIFCATION OF ABSTRACT Unclassified 